\title{
The Abuses of Argument: Understanding Fallacies on Toulmin's Layout of Argument
}

\author{
ANDREW PineaU \\ Department of Philosophy \\ McMaster University \\ 1280 Main Street West \\ Hamilton, $O N$ \\ Canada L8S $4 L 8$ \\ andrewpineau@hotmail.com
}

\begin{abstract}
This paper provides a preliminary account of fallacies on Toulmin's model of argument, one that improves upon previous attempts to understand fallacies on this argument scheme. To do this Johnson and Blair's (1983) taxonomy of three basic fallacies (irrelevant reason, hasty conclusion and problematic premise) is examined using Toulmin's layout.
\end{abstract}

Résumé: Cet article emploie le modèle d'argumentation de Toulmin pour fournir un compte rendu préliminaire des sophismes et pour améliorer les tentatives précédentes de comprendre les sophismes. Pour ce faire, la taxonomie de trois erreurs de base (raison non pertinente, conclusion hâtive et prémisse problématique) de Johnson et Blair (1983) est examinée en utilisant le modèle de Toulmin.

Keywords: backing, data, fallacy, J. Anthony Blair, qualifier, Ralph H. Johnson, Stephen Toulmin, Toulmin model, warrant

\section{Introduction}

To my knowledge no satisfactory attempt has been made to explain fallacies with respect to Toulmin's model of argument. Even Toulmin's own account found in An Introduction to Reasoning, a co-authored critical thinking textbook that employs his layout of argument, is rather confused and highly questionable ${ }^{1}$. This represents a significant gap in our understanding of Toulmin's model, since it remains unclear what elements of arguments we should be concerned with when analyzing fallacies using this scheme. The ultimate aim of this paper is to make headway in this matter and move us closer toward a clear and accurate account of fallacies on Toulmin's model of argument. To do this I will examine Johnson and Blair's (1983) taxonomy of three basic fallacies (irrelevant reason, hasty conclusion and

\footnotetext{
${ }^{1}$ For a good critique of the account of fallacies in An Introduction to Reasoning see Johnson (1980).

(c) Andrew Pineau. Informal Logic, Vol. 33, No. 4 (2013), pp. 531-546.
} 


\section{Andrew Pineau}

problematic premise) on Toulmin's layout. I begin this essay by showing that fallacies of irrelevant reason arise out of the fact that none of the potential warrants that could justify such inferences have a backing. Despite this fact, such arguments are assumed to have a backed warrant authorizing the step from the data to the claim. ${ }^{2}$ In the next section, I show that, there are two ways of looking at the fallacy of hasty conclusion. One way to understand the error is in terms of weak warrants. The other way to recognize the problem is in terms of improper qualification. In either case, such fallacies merely appear to have a warrant authorizing the step from the data to the claim with the degree of qualification initially given. In the following section, I show that the trouble with fallacies of problematic premise lies in the argument's data. The data often appear acceptable despite requiring further defence. I conclude the essay with some remarks about further investigation into the subject of fallacies on the Toulmin model of argument.

\section{Irrelevant reason on Toulmin's layout}

In Logical Self-Defense, an important work in the theory of argument which includes an influential taxonomy of fallacies, Johnson and Blair identify three basic fallacies: irrelevant reason, hasty conclusion and problematic premise. ${ }^{3}$ we will begin by examining "irrelevant reason" on Toulmin's layout. The fallacy of irrelevant reason occurs when the premises put forth to establish a conclusion are irrelevant to that conclusion (Johnson \& Blair, 1983, p. 36). This basic fallacy would include more specific types of fallacies such as argumentum ad hominem, argumentum ad populum and guilt by association. In Toulmin's terms we can say that the problem with these fallacies is the irrelevance of the data to the claim. However, when analyzing fallacies of irrelevant reason on the Toulmin model, the source of the problem will not be the data, but rather, the warrant ${ }^{4}$ used to legitimize the move from the data to the claim. Toulmin, Rieke and Janik (1984) identify an analogous type of fallacy (fallacies resulting from irrelevant grounds) and appear to agree that we

\footnotetext{
${ }^{2}$ I use 'data' as a singular noun throughout.

${ }^{3}$ In this essay I will be referring to the second edition of Logical Self-Defense (1983).

${ }^{4}$ For the purposes of this essay I understand the warrant, as Toulmin (1958) does: 'inference-licences' taking the form of "general, hypothetical statements, which can act as bridges, and authorise the sort of step to which our particular argument commits us" (p. 98).
} 
can trace the problem with these fallacies to an unbacked warrant (p. 143).

To illustrate, we can take the following example of argumentum ad hominem from Bailin and Battersby (2010, p. 65), which I have appropriated and modified for illustrative purposes:

ARG-1

(D1) John has been divorced three times.

So,

(C1) We should not believe anything John says.

Here the problem is that the data are irrelevant to the claim. However, if we want to explain why the data are irrelevant to the claim we need to turn our attention to the warrant $t^{5}$ used to legitimize the step from the data to the claim. As Toulmin, Rieke and Janik (1984) explain, the warrant is what makes the data relevant to the claim (p. 123). And as Toulmin (1958) elaborates, "we should not even know what sort of data were of the slightest relevance to a conclusion, if we had not at least a provisional idea of the warrants acceptable in the situation confronting us" (p. 106). Thus, when it comes to the relevance (or irrelevance as the case may be) of the data to the claim, we need to look at the argument's warrant.

However, at this point we run into some difficulty. Given the fact that warrants are always implicit (Toulmin, 1958, p. 100 ) or at least generally implicit, one may wonder how we could understand this fallacy if no warrant is given by the arguer. For example, the arguer may claim to be unable to identify the warrant he or she used or it may not be immediately apparent to an interpreter what specific warrant was intended by the arguer. How can we determine whether or not an argument commits this fallacy when we are not given a warrant?

Firstly, as Toulmin (1958) explains, "[t]he warrants to which we commit ourselves are implicit in the particular steps from data to claims we are prepared to take and to admit" ( $\mathrm{p}$. 100). Thus, even if no warrant is given or recognized by the arguer, he or she is still implicitly committed to some warrant when moving from data to a claim. The question then is, how do we determine which warrant was used? We certainly would not be able to determine whether or not an argument commit the fallacy of irrelevant reason if we have no warrant to work with. I think Hitchcock's (2003) characterization of the warrant would be of use here. He explains that "[i]f it is not possible to ask the 


\section{Andrew Pineau}

author of an argument, 'How do you get from your grounds to your claim?' [i.e. 'What warrant did you use?'], the question is better construed as the question, 'How might you get there? [i.e. 'What warrant could you use?']' (p. 73). In other words, when a warrant is not given, we can speculate what warrants the arguer might have relied on. Once we have a reasonable grasp of these possible warrants, we can then be in a position to determine whether or not the argument commits the fallacy of irrelevant reason. Of course an exhaustive list of all potential warrants will not always be possible depending on the situation and the argument, but one should have a reasonable grasp of the possible warrants that could be used or at least the most likely warrants that could be used.

Since, according to Toulmin (1958), the warrant is given its authority only by a backing (p. 103) we can take it that the irrelevance of the data to the claim in ARG-1 can be traced to the fact that none of the warrants (or at least none of the most plausible of these warrants) that could be used to authorize the move from (D1) to (C2) has an available backing to give the warrants any force. They must all be unbacked because, if there were a warrant among the potential warrants that did have an available backing, the charitable interpretation would be to assume the arguer used the backed warrant. Looking at ARG-1 again, there are no backed warrants that could authorize the step from (D1) to (C1). Some of the possible warrants that could be used are "If someone has been divorced multiple times then they should not be believed" and "Given information about someone, we should not believe what that person says". These and all other warrants that could legitimize the step from (D1) to (C1) will lack a backing. Without any backed warrants, there can be no relevance between the data and the claim. Hence, this is the source of the irrelevance in this and all arguments where the premises are irrelevant to the conclusion.

One may question why a warrant like (W1) "Given information about someone, we should not believe what that person says" has no backing. Surely some information about John could be relevant to claims like (C1). For example, (D1*) "John is a compulsive liar" is information about John and is highly relevant to $(\mathrm{C} 1)$. Should this not mean this warrant has some degree of backing? It might seem like (W1) should be backed for this reason, but because the warrant accounts for relevance, we should not. To give a backing to a warrant is to say that all data of the type indicated is to some degree relevant to the type of claim indicated. In other words, to give a backing to (W1) would be to say that any information about a person is to some degree relevant to claims that we should not believe that person. How-

(C) Andrew Pineau. Informal Logic, Vol. 33, No. 4 (2013), pp. 531-546. 
ever, there is a lot of information about John that would be irrelevant to (C1). If we gave a backing to (W1) we would be forced to say that claims like "John enjoys going to the zoo" or "John owns two dogs" are relevant to (C1). It is because of this that we should expect (W1) to have no backing. How then, do we account for the relevance of information such as (D1*) to claims such as (C1)? The answer is simple: they rely on their relevance from some other warrant. For example, the much more acceptable warrant "If someone is a compulsive liar, then we should not believe what they say" could authorize the step from (D1*) to (C1). This warrant could have the fairly strong backing "compulsive liars obscure the truth" and thus, confer a high degree of relevance between data like (D1*) and claims like (C1).

While it has been determined that the irrelevance of a set of data to a claim arises out of that fact that none of the (most plausible) warrants that could authorize the step from the data to the claim have a backing, we still do not have an adequate account of the fallacy of irrelevant reason. This is because not all arguments with irrelevant premises are fallacious. Some cases of irrelevance are so obvious that they would never convince an interlocutor of the claim. But, as Johnson and Blair (1983) acknowledge, "a significant feature of most fallacies is that they counterfeit sound patterns of reasoning (p. 98). That is to say, fallacious arguments often seem like good arguments. This is also alluded to by Toulmin, Rieke and Janik (1984) in their definition of fallacies as arguments that can seem persuasive despite being unsound" (p. 132). In order to have an adequate account of fallacies on the Toulmin model, we need to incorporate the fraudulent nature of fallacious arguments. In the case of fallacies of irrelevant reason this comes from the assumption of a backed warrant. Thus, what makes an argument an instance of the fallacy of irrelevant reason is not only that none of the potential warrants is backed, but also the that there is assumed to be a backed warrant that authorizes the step from the data to the claim. If we turn our attention to ARG-1 again, it is a fallacy of relevant reason not only because none of the potential warrants that could be used to move from the data to the claim have a backing, but also because it is assumed to have a backed warrant to authorize the step from (D1) to (C1).

It is important to note that we need not identify any particular warrant that is assumed to have a backing despite lacking one, nor do we need to identify the particular backing assumed to give the warrant force. We only need to recognize that it is assumed to be a legitimate step (and thus, that there is $a$ warrant with $a$ backing that is assumed to authorize it). Since the warrant generally remains implicit, the source of the error in this fallacy

(C) Andrew Pineau. Informal Logic, Vol. 33, No. 4 (2013), pp. 531-546. 
will usually be implicit as well. This is important because, as Toulmin, Rieke and Janik (1984) point out, "[w] hen the warrant is made explicit it usually becomes clear that the principle upon which the argument rests is dubious even though it did not originally appear to be" (p. 132). That is, when we make the warrant explicit, the argument is less likely to appear cogent because the problem with the underlying assumption has been exposed. If we make the warrant explicit in ARG-1, for example, it could makes the problem of irrelevance easier to see and, thus less likely to convince an interlocutor.

Thus, we have determined, much like Toulmin, Rieke and Janik (1984) that fallacies of irrelevant reason have their source in the warrant and backing. However, this account is more sensitive of the implicit nature of the warrant. We can still identify this fallacy even when no warrant is given. We merely must consider all of the possible warrants (or at least the most likely warrants) and determine whether or not all of them lack a backing. Then we must consider whether or not it is assumed to be a legitimate step despite the lack of backed warrants.

\section{Hasty conclusion on Toulmin's layout}

The second of the three basic fallacies is called 'hasty conclusion' and it occurs when the premises of an argument are insufficient to establish the conclusion (Johnson \& Blair, 1983, p. 41). Hasty conclusion includes specific fallacies such as argument from ignorance, anecdotal evidence and hasty generalization. There are two possible ways of sourcing the problem of this fallacy on Toulmin's layout. The first is to hold the degree of qualification of the claim fixed and consider the strength of the potential warrants as the problem. The second is to hold the strength of the warrant fixed and consider the degree of qualification as the source of the problem.

To demonstrate the role the warrant and qualifier can play we can look to the following case of anecdotal evidence which I have encountered in response to a recent University of Western Ontario study that purportedly shows that regular consumption of eggs is bad for one's health:

ARG-2

(D2) My grandfather ate an egg every morning and lived a long and healthy life.

(C) Andrew Pineau. Informal Logic, Vol. 33, No. 4 (2013), pp. 531-546. 
Therefore,

(C2) The regular consumption of eggs is not bad for anyone's health.

Here we can see that the data are relevant to the claim, but it is insufficient to establish it. One might be inclined to say that the problem with this argument, as is the case with arguments that commit the fallacy of irrelevant reason, lies in the fact that all potential warrants lack a backing. Toulmin, Rieke and Janik (1984) seem to lean toward this opinion in the section on fallacies of insufficient data, pointing out a warrant with an "untrue" backing in one example (p. 155). However, the problem with such fallacies cannot be that the warrant lacks a (true) backing. This is because the warrant is the source of relevance between the data and the claim (ibid. p. 106). If all the potential warrants for ARG-2 lacked a backing, then they would all have no authority. And if they all had no authority, then there could be no relevance between (D2) and (C2). However, there is some relevance between (D2) and (C2), minimal as it may be, so we should expect there to be at least one warrant that has some minimal degree of backing giving the warrant some minimal authority.

Since we are understanding relevance through the warrant and since warrants only have authority if they have a backing, then we must acknowledge that any argument where the data are relevant to the claim, even if it is insufficient to establish it, will have at least one warrant which has some degree of backing. Of course the strength of the relevance conferred by the warrant can vary, but this degree of force conferred by the warrant is going to depend on the strength of the backing. If a warrant is weakly backed, then data of the sort indicated by the warrant will be minimally relevant to the sort of claim indicated. Where the warrant is very strongly backed, the sort of data it indicates will be highly relevant to the sort of claim. And of course, there are many degrees of warrant strength in between these two extremes. Toulmin (1958) acknowledges the variable strength of warrants when he states that warrants can "confer different degrees of force on the conclusions they justify" and he points out that these varying degrees of force are reflected in the qualifier of an argument (pp. 100-101). Those warrants with a weaker backing will require us to strictly qualify our claims with qualifiers like "Possibly...", "It could be the case that...", "It is not out of the question that...", etc. Those that are strongly backed, on the other hand, can confer a great degree of strength on the claim, such that we can state the claim without any qualification 
or, if the warrant is strong enough, use the qualifier "necessarily".

As a result of this relationship between the strength of the warrant and the qualifier, we can look at the problem with ARG2 in two ways. The first is to hold the strength of the qualifier constant. In ARG-2, (C2) is stated unequivocally; it is not prefixed by any qualifier such as "possibly", "likely", etc. The problem with ARG-2, when holding the qualifier fixed, is that none of the potential warrants that could authorize the step from (D2) to (C2) are strong enough to authorize the move from (D2) to the unequivocal statement of $(\mathrm{C} 2)$. The easiest way to charitably analyze the argument is to examine the strongest possible warrants that could authorize the step from (D2) to (C2). One such warrant is (W2) "If one person lives a long and healthy life on a diet that involves the daily consumption one egg, then we can take it that eating eggs is not bad for anyone's health". The data referenced by the warrant is minimally relevant to such a claim so this warrant should have a rather weak backing. One of the strongest potential backings for (W2) is "One case of something having no deleterious health effects on a person slightly increases the chances that this thing is not unhealthy for anyone". This, however, is a very weak backing, which gives the warrant very little force and leaves it open to many rebuttals. Since none among the strongest warrants can authorize the move from (D2) to the unqualified statement (C2), we can say that the problem with ARG-2 is that none of the strongest warrants are strong enough to state $(\mathrm{C} 2)$ without qualification.

However, if we hold the warrant strength in ARG-2 fixed, then the problem will be with qualification of (C2). In the spirit of charity, we should fix the strength of the warrant to reflect the strongest warrants available, such as (W2). It is important to note that there is nothing necessarily wrong with a warrant, like (W2), that has a weak backing. Such warrants merely have little force and can only be used to establish a claim with a high degree of qualification. If a weakly backed warrant is used along with acceptable and appropriate data to make a claim with a high degree of qualification, then there is no problem with the inference. If (C2) was qualified with, for example, "possibly", then there would be nothing wrong with ARG-2. It is when such a claim is not properly qualified that a problem of insufficiency arises. Thus, the problem with ARG-2, when holding the strength of the warrant fixed, is not that the warrant is weak, but the fact that $(\mathrm{C} 2)$ is stated without the proper qualification. The strongest possible warrants that could be used to authorize the step from (D2) to (C2) are very weakly backed and so have very little force. Given (D2), we can only assert (C2) with a high de-

(C) Andrew Pineau. Informal Logic, Vol. 33, No. 4 (2013), pp. 531-546. 
gree of qualification. Rather than, "The regular consumption of eggs is not bad for anyone's health", one could only assert something such as "It is possible that the regular consumption of eggs is not bad for anyone's health" or "It is not out of the question that the regular consumption of eggs is not bad for anyone's health". Thus, from this way of looking at the problem, the qualifier (or lack thereof) used is the issue and not the warrant or backing.

I think that the former type of analysis (in terms of weakly backed warrants) better reflects how we generally tend to analyze fallacies of hasty conclusion. In such cases, we tend to think that the data are relevant, but not enough to establish the claim (with the degree of qualification stated). However, I think the latter way of analyzing this fallacy (in terms of improper qualification) can be useful too. It identifies the source of the fallacy in such a way that allows for the problem to be easily fixed. One can always add a qualification to his or her claims if it turns out that the data are relevant, but not strong enough to establish the claim as initially stated. On the other hand, I suspect one who commits the fallacy of hasty conclusion will often not have enough data (and so no warrant strong enough) to establish the claim with the degree of qualification originally stated. This could be because there is no such data or that such data is unavailable in the context of the argument. As a result, the problem of insufficiency, understood as a problem with the warrant, cannot be fixed, at least in the original context. In addition to this benefit to the qualification approach to the fallacy of hasty conclusion, it is also natural given the separation of the qualification from the claim and relation between the warrant and the qualifier. But I believe both approaches can be useful when analyzing fallacies on Toulmin's model.

As with the previous fallacy, we need to include the fraudulent nature of hasty conclusion into our conception. Regardless of how we choose to interpret this fallacy (as a problem with the warrant or qualification), this is found in the assumption that there is a warrant that could authorize the step from the data to the claim with the degree of qualification indicated when in fact there is not. Looking at ARG-2 again, we say it's a fallacy of hasty conclusion because it is assumed to have a warrant that can authorize the step from (D2) to the unqualified claim (C2). Also like the fallacy of irrelevant reason, we need not identify any particular warrant that appears to confer this degree of force or the backing giving the warrant this force. We need only recognize that one such warrant appears or is assumed to have such force. 
Toulmin, Rieke and Janik (1984) do identify a fallacy called "fallacies arising from defective grounds" which is more or less parallel to Johnson and Blair's hasty conclusion. While they say with respect to one example of insufficiency that the warrant is very weak (p. 151) ${ }^{6}$ and at one point even mention that we can fix a fallacy of insufficiency by qualifying our claim (p. 179), their conception of the role of the warrant is unclear and the role of the qualifier is not thoroughly considered. As we already saw, Toulmin, Rieke and Janik (1984) identify a fallacy of insufficiency as having an "untrue" backing (p. 155) which should not be the case if the data are relevant to the claim. They do mention that a failure to properly restrict a claim is the problem with poisoning the well (p. 164). However this specific fallacy is grouped under type of fallacy called "fallacies resulting from unwarranted assumptions". This type of fallacy is highly unclear because it is not apparent what holds this group together. Many of the specific fallacies that Toulmin, Rieke and Janik (1984) group under this heading seem like they belong elsewhere. For example, false cause seems like it should fall under fallacies of insufficiency and false analogy seems like it should fall under the type of fallacy we will deal with next, problematic premise.

In the case of fallacies of hasty conclusion, then, it has been determined that there are two ways of looking at the problem. One is in terms of a weak warrant and one is in terms of improper qualification. Either way, such arguments often appear to have a warrant that authorizes the move from the data to the claim with the degree of qualification indicated when, in fact, there is no such warrant. And much like in the case of fallacies of relevance, this conception is sensitive to the implicit role the warrant plays in recognizing this fallacy. We need not pick out any particular warrant that confers undue strength, but merely recognize that there is assumed to be one.

\section{Problematic premise on Toulmin's layout}

The final basic fallacy identified by Johnson and Blair is 'problematic premise' and it occurs when an undefended premise that ought to be defended is used to establish a conclusion (Johnson $\&$ Blair, 1983 p. 47). This fallacy, regarding premise acceptability, would include recognizable fallacies such as slippery slope, straw man, false dichotomy and false analogy. They all involve

\footnotetext{
${ }^{6}$ Saying that the warrant in the example "is open to a devastating rebuttal" (p. 152).
}

(C) Andrew Pineau. Informal Logic, Vol. 33, No. 4 (2013), pp. 531-546. 
the use of premises that, in the circumstances of the argument, require further defence. While the warrant is needed in order to authorize the step from the unsupported data to the claim, the warrant itself will not necessarily be problematic. In cases of problematic premise, the problem lies in the argument's data. To illustrate this, consider the following common slippery slope argument on assisted suicide:

\section{ARG-3}

(D3) The legalization of assisted suicide will eventually lead to murder.

So,

(C3) assisted suicide should not be made legal.

At least one of the many possible warrants that could be used to legitimize the step from (D3) to (C3) has a backing. For example, this argument could use the warrant, "If something leads to murder, then that thing should not be legal" and this warrant could be strongly backed by "Murder is wrong". So in the spirit of charitable interpretation, we can interpret the argument as using one of these strongly backed warrants. Yet, while there is no problem with the warrant or backing, this argument commits the straw man fallacy. The source of the fallacy in this argument is the data used by the arguer. The information serving as the argument's data is left undefended or under-defended despite needing further defense, so the step from data to claim is not successful, even though the warrant is backed. This is true for all fallacies of problematic premise.

As with irrelevant reason and hasty conclusion, not all arguments with problematic premises will be fallacies since some premises are so obviously problematic or unacceptable that they would never convince an interlocutor of the claim even if the warrant is backed. If our concern is fallacies, we want to narrow our focus to data that appear acceptable despite requiring further defence.

We must be cautious, though, when it comes to begging the question. Begging the question, which can be considered as a special case of the problematic premise fallacy, cannot be explained by looking at the argument's data alone. To explain this, I have appropriated an example of begging the question from Johnson and Blair (1983, p. 56) and analyzed using Toulmin's terms: 
ARG-4

(D4) Abortion is the murder of an innocent fetus.

So,

(C4) Abortion is wrong.

Again, in this case we can identify a warrant to authorize the step from (D4) to (C4) ("If something involves the murder of an innocent fetus, it is wrong") and this warrant could have a strong backing ("By definition, murder is wrong"). Thus, the warrant and backing will not be the problem. Again, it is the argument's data that are our concern. However, when we look to see what makes this argument a case of begging the question, we cannot merely look to (D4); we also must look to (C4). This is because begging the question, as Johnson and Blair (1983) define it, involves an argument where either the premises contain the conclusion or the premises are acceptable only if the conclusion has already been accepted (p. 58). Since begging the question involves this relation between the premises and the conclusion, we cannot look to the data alone as the source of the problem. We will find that it lacks an adequate defence, but without the aforementioned relation to the conclusion, we cannot tell whether or not the argument begs the question. (D4) is a premise that requires further defence, but this alone does not make it circular. It is the fact that the (C4) is presupposed by (D4) or that (D4) is acceptable only if the (C4) has already been accepted. Thus, with begging the question, we must not only focus on the data of an argument, but the claim as well.

In An Introduction to Reasoning, there is no type of fallacy that is analogous to problematic premise. This is a relatively substantial omission since many commonly recognized fallacies fall under this basic type. Toulmin, Rieke and Janik (1984) do identify a type of fallacy called "fallacies resulting from missing grounds" which includes begging the question, a specific fallacy that could be considered a special case of the problematic premise fallacy in Johnson and Blair's taxonomy. However, this is the only real type of argument that Toulmin, Rieke and Janik (1984) identify where the data are the source of the problem. Most other types tend to focus more on the warrant and backing to some extent and so fallacies where the data are the source of the problem are virtually neglected ${ }^{7}$. The above account of problematic premise on Toulmin's layout is a start towards correcting this oversight.

\footnotetext{
${ }^{7}$ And even with begging the question Toulmin, Rieke and Janik (1984) look to the warrant to spot the problem in one case (p. 137).
}

(C) Andrew Pineau. Informal Logic, Vol. 33, No. 4 (2013), pp. 531-546. 


\title{
5. Conclusion and prospects for fallacy theory on Toulmin's layout
}

In the introduction to the section on fallacies in An Introduction to Reasoning, Toulmin, Rieke and Janik (1984) maintain that,

\begin{abstract}
[w]hen we suspect fallacious reasoning we tend to be more concerned with the warrant and backing. Even if a fallacy is principally a matter of inadequate grounds, explaining what is fallacious in the argument will almost inevitably raise questions about the warrant and backing (p. 133).
\end{abstract}

However, they may have put too much stock into this claim because their account of fallacies severely underplays the role of the qualifier and the data. With the fallacy of irrelevant reason, the source of the problem is with warrants and their lack if backing. However, the source of the fallacy of hasty conclusion can be viewed in two ways: as arising from weakly backed warrants or as arising from improper qualification. Lastly, in the case of problematic premise, a class of fallacies that Toulmin, Rieke and Janik virtually neglect, the warrant and backing will not necessarily be problematic. The source of the problem with this fallacy is the argument's data. However, when we are concerned with arguments that beg the question, we also need to turn our attention to the claim in relation to the data.

While this account provides us with a preliminary understanding of fallacies on the Toulmin model, one that I hope improves upon that given in An Introduction to Reason, it is by no means exhaustive. For instance, while the above account of fallacies has focused on arguments with implicit warrants and backing, there could be fallacious arguments where the warrant and backing are made explicit. For example, one may cite a warrant that does not actually fit the type of data or type of claim cited in the argument, but which appears to. Also, the use of a backing that does not actually give the warrant authority, but appears to, is a move that is fallacious in nature. This more thorough analysis of the role of the backing in fallacies might involve looking at the use (or misuse) of 'legitimation inferences' proposed by Goodnight (1993) which serve to justify the backing used for the warrant. It might also be worth investigating fallacies regarding the rebuttal. Through the disregard or concealment of a rebuttal, an arguer could make the warrant appear stronger than it actually is. Additionally, a challenger might present an unsubstantiated rebuttal and successfully weaken the authority of the warrant. Such moves have the trademark characteristics of fallacies and would add a dialectical dimension to the

(C) Andrew Pineau. Informal Logic, Vol. 33, No. 4 (2013), pp. 531-546. 


\section{Andrew Pineau}

analysis of fallacies on Toulmin's layout. And while it has not been touched on in this paper, it would be worth analyzing the final type of fallacy which Toulmin, Rieke and Janik (1984) identify, "fallacies resulting from ambiguities" to determine the source of each problem on Toulmin's layout. Finally, there is the question of how to understand and diagram formal fallacies. For example, where on the Toulmin model does the problem lie with the fallacy of affirming the consequent? Fairbanks (1993) has cited the inability to recognize formal fallacies as a problem with Toulmin's layout (p. 112), but I believe an acceptable inquiry on the matter has yet to be conducted. Despite the work that has been done in this paper, there are still many possibilities and many unanswered questions with regard to fallacies on Toulmin's layout.

Another issue I think is worthy of further investigation is whether or not a taxonomy of fallacies is compatible with Toulmin's field-dependency thesis. The account of fallacies presented by Toulmin, Rieke and Janik in An Introduction to Reasoning has been criticized on this matter. Rowland (1982) argues that the discussion of fallacies in An Introduction to Reasoning does not square with the idea of field-dependence in The Uses of Argument (p. 231) and actually involves field-invariant standards (Rowland, 1981, p. 76). Although Toulmin, Rieke and Janik (1984) themselves seem to admit that there are no fieldinvariant types of fallacies when they say that we cannot "identify any intrinsically fallacious forms of argument" (p. 131), I do not think a field-invariant account of fallacies is out of the question. In fact, I think the account of the three basic fallacies given above is field-invariant. Toulmin's field-dependency thesis is preserved because, while the conceptions above are fieldinvariant, whether or not an argument actually qualifies as one of these fallacies will depend on the field. This fits well with Toulmin, Rieke and Janik's (1984) important claim, that, "[a]rguments that are fallacious in one context may turn out to be quite solid in another context" (p. 131). Willard (1989) says that this is a remarkable claim in a field whose textbook contain a list of fallacies" (p. 226), but I do not believe it to be totally untenable to have a taxonomy of fallacies while also admitting that fallacies are contextual. As Johnson and Blair (1993) have pointed out, whether or not a given type of fallacy could be sound in some contexts is all in how you define the fallacy.

Incorporating Toulmin's field-dependency thesis (or some contextual element) into the analysis of fallacies would be important because it would provide the criteria for the acceptability of data, warrants and backings which would help us determine which arguments fit under each of the three basic fallacies and

(C) Andrew Pineau. Informal Logic, Vol. 33, No. 4 (2013), pp. 531-546. 
in which contexts those arguments should be considered fallacies. Admittedly, this account explains the structural problems with certain fallacious arguments, but does not provide any criteria for things such as when a warrant is backed or not or how much force a given warrant has. I believe such criteria depend on the context of the argument and so a contextual theory of argument analysis would be a useful supplement to the present theory of fallacies on Toulmin's layout.

I think it is also important to point out that this paper has focused on fallacies understood as logical flaws in arguments. Thus, it has not been considered how, or if at all, the Toulmin model can accommodate dialectical conceptions of fallacies such as those developed in pragma-dialectical theory such as van Eemeren \& Grotendorst (1992).

Lastly, since the account of fallacies just presented is based largely around a taxonomy first presented in 1977, it will likely need some further refinement to better capture the understanding of fallacies that has developed in the literature subsequently. However, I think we are now much closer to proper account of fallacies on Toulmin's model of argument.

Acknowledgements: I would like to thank David Hitchcock, Ben Hamby, Bart Garssen, J. Anthony Blair, David Godden and James Freeman for their very helpful and insightful comments on early drafts of this paper.

\section{References}

Bailin, S. \& Battersby, M. (2010). Reason in the Balance: An inquiry approach to critical thinking. Whitby, ON: McGrawHill Ryerson.

Eemeren, F.H. van \& Grootendorst, R. (1992). Argumentation, Communication and Fallacies, Hillsdale, NJ: Lawrence Erlbaum.

Fairbanks, A.H. (1993). The pedagogical failure of Toulmin's logic. The Writing Instructor, 12(3): 103-114.

Goodnight, G.T. (1993). Legitimation inferences: An additional component for the Toulmin model. Informal Logic, 15: 4152.

Hitchock, D. (2003). Toulmin's warrants. In F.H. van Eemeren, J.A. Blair, C.A. Willard, A.F. Snoeck Henkemans (Eds.), Anyone Who Has a View: Theoretical Contributions to the Study of Argumentation, pp. 83-90. Dordrecht, The Netherlands: Kluwer Academic Publishers. 
Johnson, R.H. (1980). Toulmin's bold experiment. Informal Logic, 3(3): 13-19.

Johnson, R.H. \& Blair, J. A. (1983). Logical Self-Defense, $2^{\text {nd }}$ ed.. Toronto: McGraw Hill Ryerson.

Johnson, R.H. \& Blair, J.A. (1993). Dissent in fallacyland, Part 2: Problems with Willard. In R.E. McKerrow (Ed.), Argument and the postmodern challenge: Proceedings of the eighth NCA/AFA conference on argumentation, pp. 191-193. Annandale, VA: Speech Communication Association.

Rowland, R. C. (1981). Argument fields. In G. Ziegelmueller \& J. Rhodes (Eds.).

Dimensions of Argument: Proceedings of the Second Summer Conference on

Argumentation, pp. 56-79. Annandale, VA: Speech Communication Association.

Rowland, R.C. (1982). The influence of purpose on fields of argument. Journal of the American Forensic Association, 18(4): 228-245.

Toulmin, S.E. (1958). The Uses of Argument. Cambridge: Cambridge University Press.

Toulmin, S., \& Rieke, R., \& Janik, A. (1984). An Introduction to Reasoning, $2^{\text {nd }}$ ed.. New York: Macmillan.

Willard, C.A. (1989). A Theory of Argumentation. Tuscaloosa, AL: University of Alabama Press. 